\title{
Nothing is fair or good alone
}

Niloo M. Edwards, MD ${ }^{\text {a }}$

Kenneth M. Prager, MD

See related article on page 49 .

It is doubtful if many doctors who actually care for the sick and the infirm, plan their actions on the basis of the predicted effect upon society. Instead, the dominant tradition is for the physician to provide the best care of which he is capable for those who either seek his services or are assigned to his responsibility; by and large this is done without regard for the conceivably broader issue of whether treatment is justifiable on social grounds.

Transplantation Proceedings, 1966

From the Departments of Surgery ${ }^{\mathrm{a}}$ and Medicine, Columbia College of Physicians and Surgeons, and the Departments of Cardiac Transplantation ${ }^{\mathrm{b}}$ and Clinical Ethics, Columbia-Presbyterian Medical Center, New York, NY.

Received for publication Sept 13, 2002; accepted for publication Oct 1, 2002.

Address for reprints: Niloo M. Edwards, MD, 7-435 MHB, 177 Fort Washington Ave, Columbia-Presbyterian Medical Center, New York, NY 10032 (E-mail: nme3@columbia.edu).

J Thorac Cardiovasc Surg 2003;125:23-4

Copyright $(\odot) 2003$ by The American Association for Thoracic Surgery

$0022-5223 / 2003 \$ 30.00+0$

doi:10.1067/mtc.2003.63

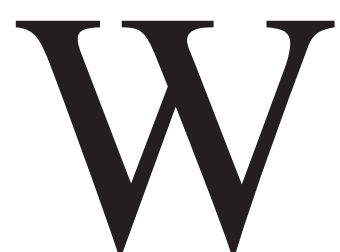

e are never more torn between our desire to do what is best for the patient and what is best for society as a whole than in the field of transplantation, where the shortage of organs has led to a policy of distributing this scarce resource on the basis of organ survival rather than strictly on patient need. In medical ethics terminology, it is a conflict between beneficence, doing what is best for our patients, and justice, the fair societal allocation of a scarce resource. The article by Laks and associates ${ }^{1}$ suggests that not only are our current donor selection policies outdated, but so too are our recipient selection criteria, since outcomes using "non-standard" heart donors were comparable with those obtained with conventional donors even when used in less than optimal recipients.

The findings suggest an untapped source of donors, thereby increasing the potential donor pool. However, this study also indicates that "alternate list" recipients, primarily older patients, can do as well as their younger counterparts despite the handicap of a "non-standard" donor. Since the incidence and prevalence of heart failure rise exponentially with age, this increased demand for organs would greatly aggravate the already serious shortage of donors and more than outweigh the additional number of "non-standard" organ donors, inasmuch as there are more patients with heart failure between the ages of 65 and 70 years than there are from birth to 64 years. $^{2}$

More important, the findings from the University of California at Los Angeles ${ }^{1}$ raise questions concerning the ethical basis for age cutoffs. If others substantiate these findings, then transplant programs will have to face the issue of using age per se as a criterion for not offering a heart transplant. Either they can avoid charges of ageism-discrimination based on age — by raising their age cutoffs for standard hearts, or they can find ethical justification for maintaining their current age limits. One can, for example, argue that justice is served by allocating the scarce resource of a human heart to those under a certain age because a younger person has a greater entitlement than an older patient, by virtue of the greater deprivation of years of expected life span that he or she will experience by not receiving the organ. Current United Network for Organ Sharing (UNOS) policy for organ allocation certainly suggests endorsement of this viewpoint by providing potential recipients, younger than age 18 years, with a deliberate advantage by allocating all donors younger than 18 to these recipients first.

On the other hand, one can adopt a policy emphasizing allocation of resources on the basis of individual need. Daniel Callahan, ${ }^{3}$ in his controversial book Setting Limits, suggests that our current principles of providing health care are defined by 
the philosophy: "What can be done medically ought to be done. What ought to be done ought to be available to all. What ought to be available to all becomes the moral responsibility of all." Certainly, our current health-care allocation philosophy would suggest that health resources should be distributed on the basis of individual need, regardless of productivity, life lived, or social position, and that the chivalric philosophy of "women and children first" is perhaps archaic and certainly too chauvinistic to use as a principle of allocation.

Furthermore, not all patients who share the same chronologic age share the same physiologic age. Although not explicitly stated, it would appear that older patients selected for the "alternate" list were physiologically "younger" than their counterparts, who did not make this secondary list. Therefore, the broad acceptance of chronologically older patients without consideration of their physiologic age would result in poorer outcomes and poorer use of this scarce resource.

The tempestuous discussion that this article must generate is as important as the clinical ramifications, since sails of mechanical cardiac support are clearly visible on the horizon. Much as we would like to insulate our patient care role, we share a larger responsibility to all patients and, indeed, to society as a whole.

Since its introduction in 1968, heart transplantation has extended thousands of lives both quantitatively and qualitatively. In addition, the ethically sensitive process of selecting candidates has proceeded remarkably well because of scrupulous adherence to objective criteria of physiologic need. Subjective questions of individual worth have been assiduously avoided, and the playing field has been kept as level as possible. The findings by Laks and associates have provided us with a mixed blessing. While demonstrating that older patients with poorer donor hearts can survive nearly as well as younger patients with better hearts, they have forced us to consider whether and how to place limits on those who can benefit from this awesome technology.

Nor knowest thou what argument

Thy life to thy neighbour's creed has lent.

All are needed by each one;

Nothing is fair or good alone.

-Ralph Waldo Emerson

Each and All

\section{References}

1. Laks H, Marelli D, Fonarow GC, Hamilton MA, Moriguchi JD, Ardehali A, et al. Use of two recipient lists for adults requiring heart transplantation. J Thorac Cardiovasc Surg. 2001;125:49-59.

2. Robbins MA, O'Connell JB. Economic impact of heart failure. In: Rose EA, Stevenson LW, editors. Management of end-stage heart disease. Philadelphia,: Lippincott-Raven; 1998.

3. Callahan D. Setting limits: medical goals in an aging society. Washington (DC): Georgetown University Press; 1995. 